\title{
A Content Model based on LOM Specification Integrating Learning Disabilities: Toward an Adaptive Framework
}

\author{
Jaime Muñoz-Arteaga $^{1}$, Julien Broisin ${ }^{2}$, Miguel A. Ortiz-Esparza ${ }^{1}$ \\ ${ }^{1}$ Universidad Autónoma de Aguascalientes, Mexico \\ ${ }^{2}$ Institut de Recherche en Informatique, France \\ jaime.munoz@edu.uaa.mx, broisin@irit.fr, \\ miguel.ortiz@edu.uaa.mx
}

\begin{abstract}
Learning disabilities can be defined as neurologically based processing problems that interfere with basic learning skills such as understanding, reading or counting, but also with higher-level skills such as space and time coordination. Adaptive learning systems are usually not designed to take into account learning disabilities, even if the need for enhancing support of learners with disabilities is more and more important within nowadays society. We first identify the set of learning disabilities to consider in an accessible adaptive learning system; then a content model is proposed integrating the matching abilities and extending a standard to ensure interoperability with existing solutions. Finally, a case study is presented to apply the proposed model in order to identify a learning object designed to support math skills at elementary school.
\end{abstract}

Keywords: technology enhanced learning, LOM specification, learning disabilities.

\section{Introduction}

Technology Enhanced Learning (TEL) aims at supporting learning, and includes both educational and assistive technologies to improve access to educational tools and learning materials, to encourage involvement in learning activities, and to overcome barriers limiting the learning process [7]. Some of these barriers are the Learning Disabilities (LD) that can be defined as neurologically-based processing problems that interfere with basic learning skills such as understanding, reading or counting, but also with higher-level skills such as space and time coordination.

Types of learning disabilities are considered as dyslexia, dysgraphia, dyscalculia, dyspraxia and non-verbal learning disabilities [5]. Learning disabilities can also impact one's social relationships with family, friends or colleagues. They are all of different forms, but they are all learning disorders.

Unfortunately, learning systems are usually not designed to take into account learning disabilities. The approach adopted to address this problem often consists in designing systems specifically intended to learners with LD. 
One important risk of this approach is to increase social exclusion of LD learners, as they do not use the systems used by learners without LD. Yet other environments could be designed, such as adaptive systems, to adapt existing learning tools to LD learners and thus to enhance their feeling of belonging to the "regular" learning community.

Adaptive systems are usually composed of four main models [2]: (1) the learner model comprises both domain-dependent and independent characteristics of the learner, (2) the content model describes the learning resources to ensure their mapping with the previous model, (3) the tutoring model includes the adaptive techniques while de- fining what can be adapted, and (4) the user interface model specify the interaction and feedback according to user needs.

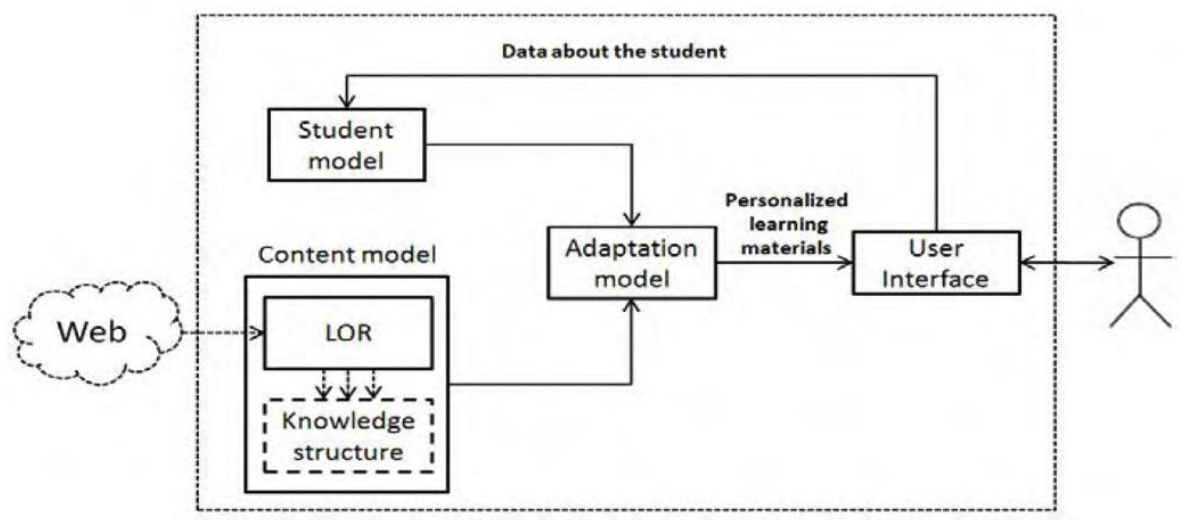

Fig. 1. Architectural model for a recommender system, inspired by [2].

Most adaptive system designed to support learning difficulties don't give information about an effective use in a teaching session [4]. Then teachers spend a lot of time in the selection of educational application according to the learning needs of their students. Learning disabilities are necessary to take into account in particular at elementary school since they reflecting a low academic performance in the child with the possibility of academic desertion [3].

Accessibility aspects can be considered throughout different models of architectural of figure 1, this work focuses only in the content model in terms of learning objects considering learning disabilities, then the content model requires to offer an explicit accessibility specification; This helps a better match with the learner model so that adaptive techniques and algorithms can be further developed [7].

Current work is structured in six sections, section two describes the theoretical background concerning the accessibility and learning object concepts. A related work is presented in section three. The proposal of current work is presented in the fourth section; it is based on standardized initiatives and extensions dedicated to the abilities previously identified.

Next section presents a case study in order to give an overview of existing adaptive approaches regarding learners with disabilities. Finally, in section six, we sum up the proposal and expose the future experimentation designed to evaluate our proposals. 


\section{Theoretical Background}

This sections presents a short description of standard LOM (Learning Object Metadata) is made, starting from the definitions of learning object and its metadata. The term learning disability is also described in order to present some research well known in TEL literature.

\subsection{Learning Object}

In the LOM standard [6] a learning object is defined as: "any entity, digital or nondigital, that can be used to learn, teaching or training". On the other hand, one of the most common and simple metadata descriptions is that they are considered as "data of the data", this information is mainly used to facilitate the identification, organization and interoperability of learning objects. In fact, the metadata is a kind of interface specifying main characteristics of a learning object [10].

Based on this definition, the metadata of learning objects can be considered as a document that contains structured information by categories and subcategories about an entity that can be used for learning and teaching purposes [6].

The general structure of this standard is composed of nine sections: General, Life Cycle, Metadata, Technical, Educational, Rights, Relation, Annotation and Classification, whose purpose is to allow mainly interoperability between various operating systems, as well as share and reuse the information in different systems or components, through the creation of LOM instances through XML (eXtensible Markup Language). Barker [1] indicates that the design and use of LOM helps us obtain a description that facilitates discovering, locating and acquiring learning resources for teachers, students and automated software processes. It also allows to produce and share the description of resources to adapt to the special needs of a community, thus controlling the vocabulary by classification and reducing the number of elements that are described or added from another resource description scheme.

\subsection{Learning Disabilities}

The term of accessibility is related to the characteristics of the environments, services and products, which include adaptations necessary to be available to all. The WWW Consortium [13] responds to this need by establishing a web accessibility initiative that provides extensive guidelines and recommendations on the characteristics that certain content must meet to make them accessible and available on various devices. In addition to this initiative, in the document COGA (Cognitive Accessibility User Research) [13], it provides information of users with learning disabilities versus cognitive disabilities, the objective of the description of this information is to provide the characteristics and difficulties in each of these problems in order to consider the accessibility characteristics that must be considered to offer services and technology for this user.

This table is an important guide to take into account in the instructional design of accessible content in terms of learning object, for example a user with any learning disability; it is necessary to consider strategies into the content to reinforce the 
memory disorder or visual recognition. In fact, this tables are the starting point to justify the accessibility concept preconized by current work.

Table 1. Learning disabilities versus cognitive function according to COGA [13].

\begin{tabular}{|c|c|c|c|c|c|c|c|c|}
\hline $\begin{array}{l}\text { Learning } \\
\text { Disabilities/ } \\
\text { Cognitive } \\
\text { Function }\end{array}$ & $\begin{array}{l}\text { Dys- } \\
\text { lexia }\end{array}$ & $\begin{array}{l}\text { Aph- } \\
\text { asia }\end{array}$ & $\begin{array}{l}\text { Non } \\
\text { Verbal }\end{array}$ & $\begin{array}{l}\text { Down } \\
\text { Synd- } \\
\text { rom }\end{array}$ & $\begin{array}{l}\text { Au- } \\
\text { tism }\end{array}$ & $\begin{array}{l}\text { Dys- } \\
\text { calculi } \\
\text { a }\end{array}$ & $\begin{array}{l}\text { Aging- } \\
\text { Related } \\
\text { CognitiveD } \\
\text { ecline }\end{array}$ & ADD \\
\hline Memory & $*$ & $*$ & $*$ & * & $*$ & $*$ & $*$ & $*$ \\
\hline $\begin{array}{l}\text { Executive } \\
\text { Functions }\end{array}$ & $*$ & $*$ & & $*$ & $*$ & $*$ & $*$ & $*$ \\
\hline Reasoning & TNA & $*$ & $*$ & $*$ & $*$ & $*$ & $*$ & TNA \\
\hline Attention & $*$ & $*$ & $*$ & $*$ & $*$ & & $*$ & $*$ \\
\hline Language & & $*$ & $*$ & & $*$ & & & \\
\hline $\begin{array}{l}\text { Speech } \\
\text { Perception }\end{array}$ & $*$ & $*$ & $*$ & $*$ & & & $*$ & \\
\hline $\begin{array}{l}\text { Understanding } \\
\text { figural } \\
\text { language }\end{array}$ & NA & $*$ & $*$ & & & & $*$ & \\
\hline Literacy & $*$ & $*$ & $*$ & * & $*$ & & $*$ & \\
\hline $\begin{array}{l}\text { Visual } \\
\text { Perception }\end{array}$ & $*$ & $*$ & $*$ & * & $*$ & $*$ & $*$ & $*$ \\
\hline $\begin{array}{l}\text { Other } \\
\text { Perception }\end{array}$ & $*$ & $*$ & $*$ & * & $*$ & $*$ & $*$ & $*$ \\
\hline Knowledge & $*$ & $*$ & $*$ & $*$ & $*$ & $*$ & $*$ & \\
\hline Behavioral & $*$ & $*$ & $*$ & $*$ & $*$ & NA & $*$ & \\
\hline Consciousness & TNA & $*$ & $*$ & & & NA & $*$ & \\
\hline
\end{tabular}

*TNA= typically not affected, NA= not affected, $\mathrm{ADD}=$ Attention Deficit Disorder.

\section{Related Work}

We have conducted a literature review focusing on content models that could be used by adaptive learning systems, to study in which extent they take into account learning disabilities [7].

Nowadays, many knowledge pools have been built to enable sharing and reuse of learning materials. Most of them implement the LOM [3] standard to describe the content they offer, which provides a controlled structure and vocabulary to expose details about the properties of a learning object. Since this standard has not been designed to support learning disabilities, several proposals emerged to integrate some of the facets of LD: Karampiperis and Sampson [11] proposed an application profile focusing on accessibility. Other approaches have been built, such as TASS [3] and PBAE [8], to facilitate the identification of accessible resources by considering the properties defined by the IMS standard, but previous works have not taken into account in an explicit manner the specification of learning disabilities into the learning object; current work represent a basis for designing a content model supporting learners with LD. 


\section{Content Model}

In order to allow systems to self-adapt according to the above learner model while preserving reuse of content stored into existing repositories, we propose a content model based on the LOM standard [6] and comprising a new category dedicated to accessibility, this expresses the level of ability required by a learner to use efficiently the learning resource. We propose in the figure 2 an extension for LOM specification for metadata of learning objects is inserting a new category called Accessibility with the COGA criteria described in the table 1. Then, the possible values for the field titled "learning disability" such as: Dyslexia, Aphasia, Non Verbal, Down Syndrome, Autism, Dyscalculia, Aging related Cognitive Decline, ADD (Attention Deficit Disorder). For the field "Cognitive function" one of values are considered: Memory, Executive Functions, Reasoning, Attention, Language, Speech Perception, Understanding figural language, Literacy, Visual Perception, Other Perception and Knowledge.

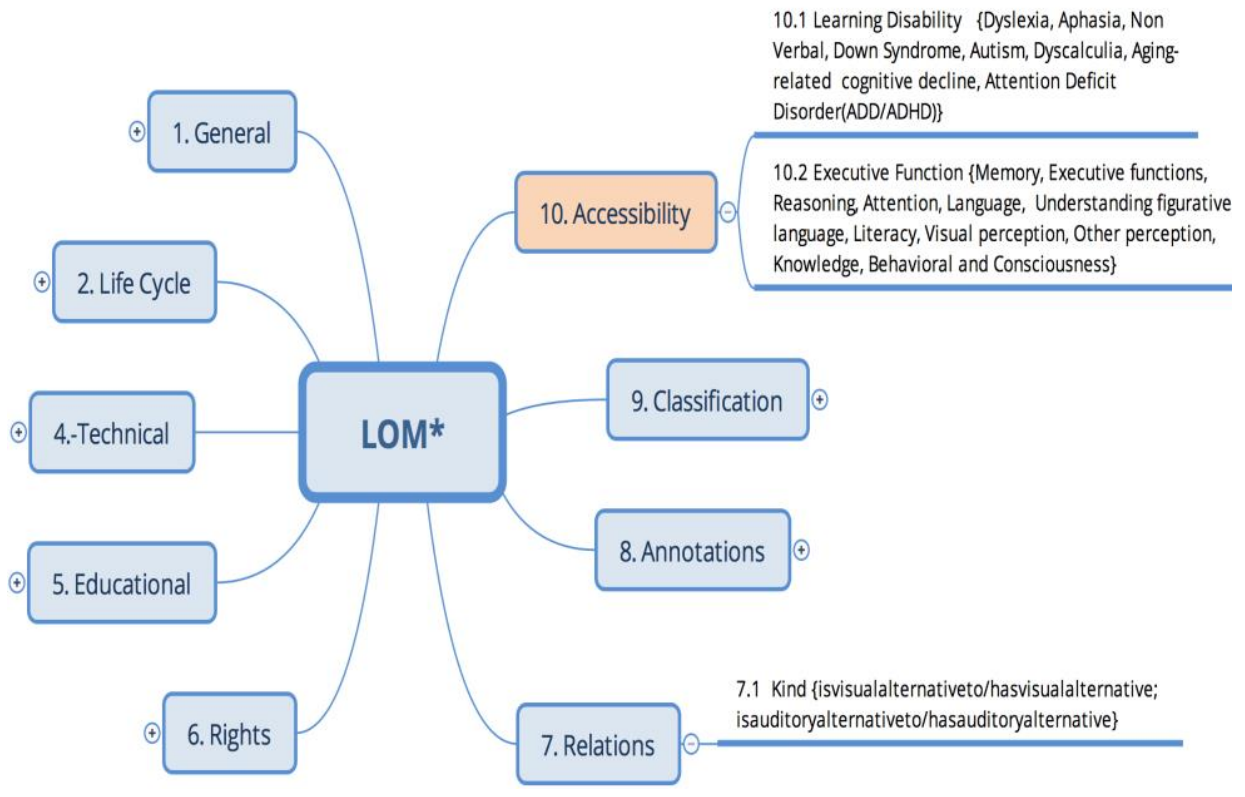

Fig. 2. Extension of IEEE LOM as a content model considering the accessibility aspect.

Also, to allow an adaptive learning systems to deliver alternative resources to learners according to their preferences, we extended the Relation category of the LOM standard. Indeed, this primary objective of this category is to depict the different kinds of relations learning resources might have between them. Therefore, to express the fact that a given learning material represents an alternative to a visual or auditory resource in a similar way of Sampson [11], we defined the new isvisualalternativeto/hasvisualalternative and isauditoryalternativeto /hasauditoryalternative kind of Relations category. Table 2 presents this information. 
Table 2. Specification for a visual or auditory content to consider in the Relations category.

\begin{tabular}{|c|c|c|c|c|c|c|c|}
\hline$\#$ & $\begin{array}{l}\mathrm{Na}- \\
\mathrm{me}\end{array}$ & Explanation & Size & Order & Value space & $\begin{array}{l}\text { Data } \\
\text { Type }\end{array}$ & $\begin{array}{c}\text { Exampl } \\
\mathrm{e}\end{array}$ \\
\hline 7 & $\begin{array}{l}\text { Rel } \\
\text { at- } \\
\text { ion }\end{array}$ & $\begin{array}{c}\text { This } \\
\text { category } \\
\text { defines the } \\
\text { relationship } \\
\text { between this } \\
\text { learning } \\
\text { object and } \\
\text { other } \\
\text { learning } \\
\text { objects, if } \\
\text { any. }\end{array}$ & $\begin{array}{l}\text { LangStri } \\
\text { ng } \\
\text { (Smallest } \\
\text { permitte } \\
\text { d } \\
\text { maximu } \\
\text { m } 100 \\
\text { items) }\end{array}$ & $\begin{array}{l}\text { Uno- } \\
\text { rde- } \\
\text { red }\end{array}$ & & & \\
\hline 7.1 & $\begin{array}{l}K i- \\
n d\end{array}$ & $\begin{array}{l}\text { Nature of } \\
\text { the } \\
\text { relationship } \\
\text { between this } \\
\text { learning } \\
\text { object and } \\
\text { the target } \\
\text { learning } \\
\text { object. }\end{array}$ & 1 & $\begin{array}{l}\text { Uns- } \\
\text { peci- } \\
\text { fied }\end{array}$ & $\begin{array}{c}\text { isviualaltern } \\
\text { ativ } \\
\text { to/hasvisual } \\
\text { alternative; } \\
\text { isadtoryalter } \\
\text { ntivto/hasau } \\
\text { ditoryalterna } \\
\text { tive }\end{array}$ & $\begin{array}{l}\text { Voc- } \\
\text { abu- } \\
\text { lary } \\
\text { (state) }\end{array}$ & $\begin{array}{l}\text { "isvisu } \\
\text { alaltern } \\
\text { ativeto/ } \\
\text { hasvisu } \\
\text { alalter- } \\
\text { native" }\end{array}$ \\
\hline
\end{tabular}

\section{Case Study}

Current proposal has applied in the following case study: a special education teacher needs to teach a student of eight years old under third grade of primary school. Dyscalculia has been the result of diagnosis conducted by the teacher, since this student has some difficulties for the identification and manipulation of numbers, in particular the child has a limited ability to grasp the concept of value of money. One of proposed solution by the teacher is one activity where the student gets skills to select, compare and buy items in a corner store.
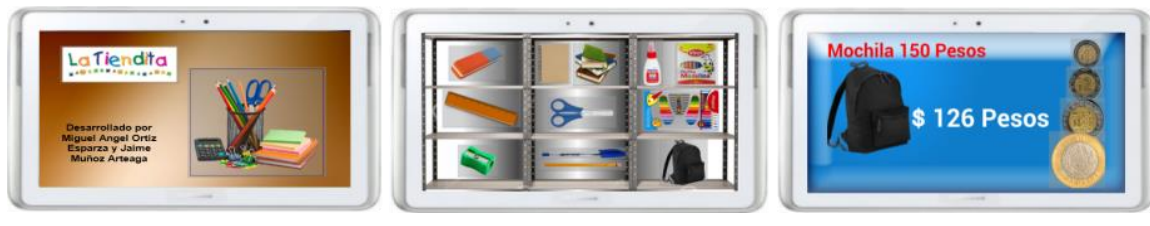

Fig. 3. User interface of learning object "La Tiendita".

The teacher has used an educational recommender system using the proposed content model to look for a learner object to support this activity, an application called "La Tiendita" is the answer given by the system (see figure 3). This is because people with dyscalculia often buying far too much or not-nearly enough because it is difficult for them to work out exactly how much they need. In order to design 
personalized functionalities such as recommendations for different user types in this case study, the recommender system should first establish a user model to represent users' profile, as well as current content model to organize and classify the resources accessed by users. It is possible to enrich their semantics in a similar approach of work [12], such models can be expressed in terms of ontology concepts.

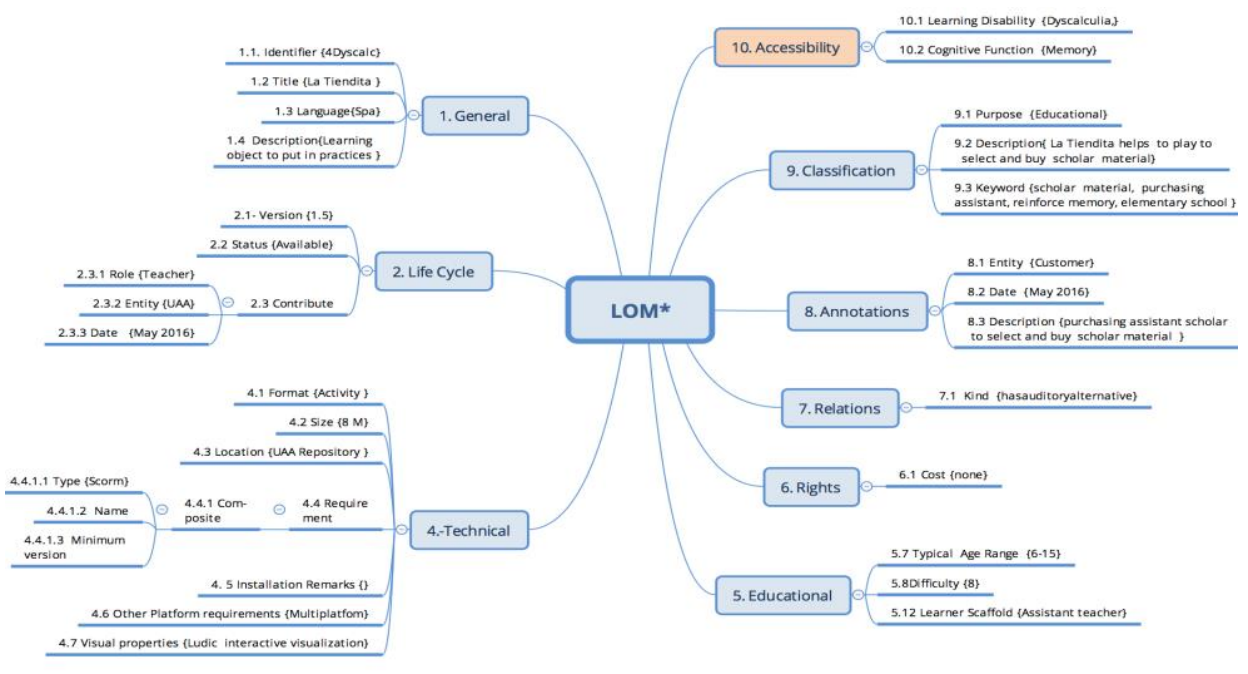

Fig. 4. Content model for the learning object "La Tiendita".

The proposed content model of figure 4 describes the characteristics of learning object "La Tiendita", note the accessibility category is described in terms of a learning disability and the cognitive function where dyscalculia is the value of learning disability and for the field cognitive function is the reasoning and memory.

The student has used the learning object called "La Tiendita" to select and play to buy scholar material such as notebooks, pencil, eraser, scissor, backpack, etc... In addition, the application helps to get and confirm an accurately payment in cash, in case of error a message is sent to user in order to give a better solution and get a successful result (see figure 3 ).

With all this information, the teacher can use the recommender system and begin with the search of learning object that allow, for example, to approach visual perception or another cognitive function. In this sense, it is possible to illustrate the need to use this extension of LOM, since the keywords that the teacher uses are related to learning problems and cognitive functions, and it is possible to find only the resources related to that category or subcategories.

\section{Conclusions and Future Work}

This paper has proposed a content model in order to design adaptive learning systems able to take into account learners with disabilities. The proposed content model extends existing standardized initiatives to ensure interoperability with existing 
solutions, and stands on the concept of learnability to consider abilities that affect the learning process [7]. There are several initiatives in progress as future work to develop the tutoring model. The adaptive rules exploit the usability features of both the learner and the content models to apply strategies for the identification of appropriate resources that can be recommended and delivered to learners according to their LD profile. For this, several user evaluations can be conducted in order to evaluate the capacity of our adaptive system to deliver pertinent resources to children in order to increase their reading skills; tutors of the children will be responsible for filling the initial profiles of learners as well as ensuring the evaluation of our adaptation process, whereas a repository $[9,10]$ comprising a set of learning objects will be used as the source of learning content.

\section{References}

1. Barker, P.: What is Ieee learning object metadata/ims learning resource metadata. Cetis standards briefings series (2005)

2. Butz, C., Hua, S., Maguire, R.: A web-based bayesian intelligent tutoring system for computer programming. Web Intelligence and Agent Systems, Vol. 4, pp. 77-97 (2006)

3. Green, S., Jones, R., Pearson, E., Gkatzidou ,S.: Accessibility and adaptability of learning objects: responding to metadata, learning patterns and profiles of needs and preferences. ALT- J, Research in Learning Technology 14(1), pp. 117-129 (2006)

4. Bustos-López, M., Vásquez-Ramírez, R., Alor-Hernández, G.: An Architecture for Developing Educational Recommender Systems. Research in Computing Science 106, pp. 17-26 (2015)

5. Hammill, D.: On Defining Learning Disabilities: An Emerging Consensus. Journal of Learning Disabilities 3(2) (1990)

6. IEEE Learning Technology Standards Committee (LTSC). Draft Standard LOM (2002)

7. Erdt, M., Fernández, A., Rensing, C.: Evaluating Recommender Systems for Technology Enhanced Learning. IEEE Transactions on Learning Technologies 8(4) (2015)

8. Jemni, M., Laabidi, M., Ben Ayed, L.: Accessible E-learning for Students with Disabilities: From the Design to the Implementation. In: Huang, R., Kinshuk, Chen, NS. (eds) The New Development of Technology Enhanced Learning. Lecture Notes in Educational Technology. Springer, Berlin, Heidelberg (2014)

9. Margain Fuentes, L., Muñoz Arteaga, J., Santaolaya Salgado, R., Alvarez Rodriguez, F., Vanderdonckt, J., Orey, M.: MIRROS: Intermediary Model to Recovery Learning Objects. Revista Computación y Sistemas 13(4) (2010)

10. Muñoz Arteaga, J., Alvarez-Rodriguez, F., Chan-Nuñez, M.E.: Tecnología de objetos de Aprendizaje. Editorial Universidad Autónoma de Aguascalientes \& UdG Virtual (2007)

11. Sampson, D., Fytros, D., Zervas, P.: Supporting Lifelong Learning Programmes: Defining an Accessibility and Competence Based Application Profile for Educational Metadata. In Proceedings of the 11th IASTED International Conference, Vol. 614, No. 125, pp. 343348 (2008)

12. Triomphe, M., Vidal, P., Broisin, J.: Opening Learner Profiles across Heterogeneous Applications. In: ICALT 2009, IEEE Computer Society, pp. 504-508 (2009)

13. W3C, Cognitive Accessibility User Research. In: Web Accessibility Initiative (WAI), http://www.w3.org/TR/coga-user-research/ (2018) 